\title{
A method for texture discrimination in the sole of the foot. A preliminary communication
}

\author{
T. S. NARAYANAKUMAR, A. SUBRAMANIAN \& \\ K. MANIVANNAN \\ Sacred Heart Leprosy Centre, Kumbakonam, India
}

Accepted for publication 12 December 1994

\begin{abstract}
Summary A new method for testing sensibility in the sole of the foot is described. In this method the ability to distinguish different surfaces while walking is assessed. This dynamic, functional and more objective test is recommended as an additional tool to evaluate sensibility in the sole of the foot.
\end{abstract}

\section{Introduction}

The assessment of nerve function is of the utmost importance in evaluating the extent of nerve damage and the result of therapy. To evaluate progress (or lack of progress) during therapy, an objective assessment is of greater value. Such an assessment also needs to be functional, as that would reflect the functional neural status from the patient's point of view. As most of the available methods are designed for assessment of the hand, there is a need for a similar method for the assessment of the sole of the foot. Hence, this simple, dynamic, functional, and more objective test has been devised.

\section{Materials and Methods}

We constructed 3 wooden trays $\left(10^{\prime} \times 2^{\prime} \times 6^{\prime \prime}\right.$ each $)$, containing either pebbles, sand, or microcellular rubber, filled to the height of $4^{\prime \prime}$ and fixed, so that the materials did not become displaced in the tray. The trays were covered with identical thin, smooth cloth and provided with wooden platforms on 1 side, which was at the same level as the sand pebbles or rubber in the tray (Figure 1).

Patients were blindfolded ${ }^{4}$ and led to walk with 1 foot on 1 of the trays and the opposite foot on the adjacent platform (Figure 2). In this way they were led to walk on all 3 surfaces, 3 times each in a random fashion, and the patient's observations were recorded. Texture discrimination was taken as positive only when they sequentially identified the surfaces on all 3 occasions. The test was repeated for the opposite foot.

Before any clinical application, 20 of our staff members with normal sensibility were tested and all of them were able to identify the surfaces correctly. 


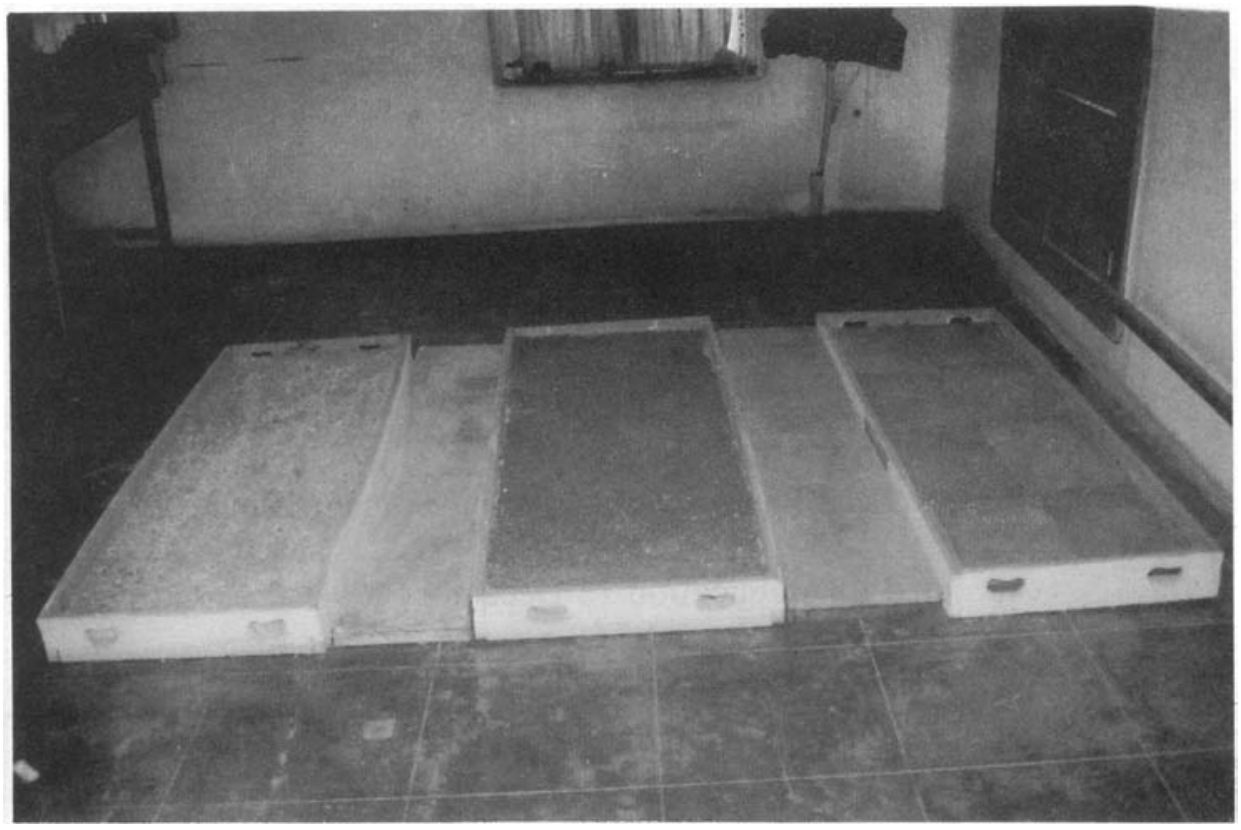

Figure 1. The 3 wooden trays containing pebbles, sand and microcellular rubber, with platforms in between.

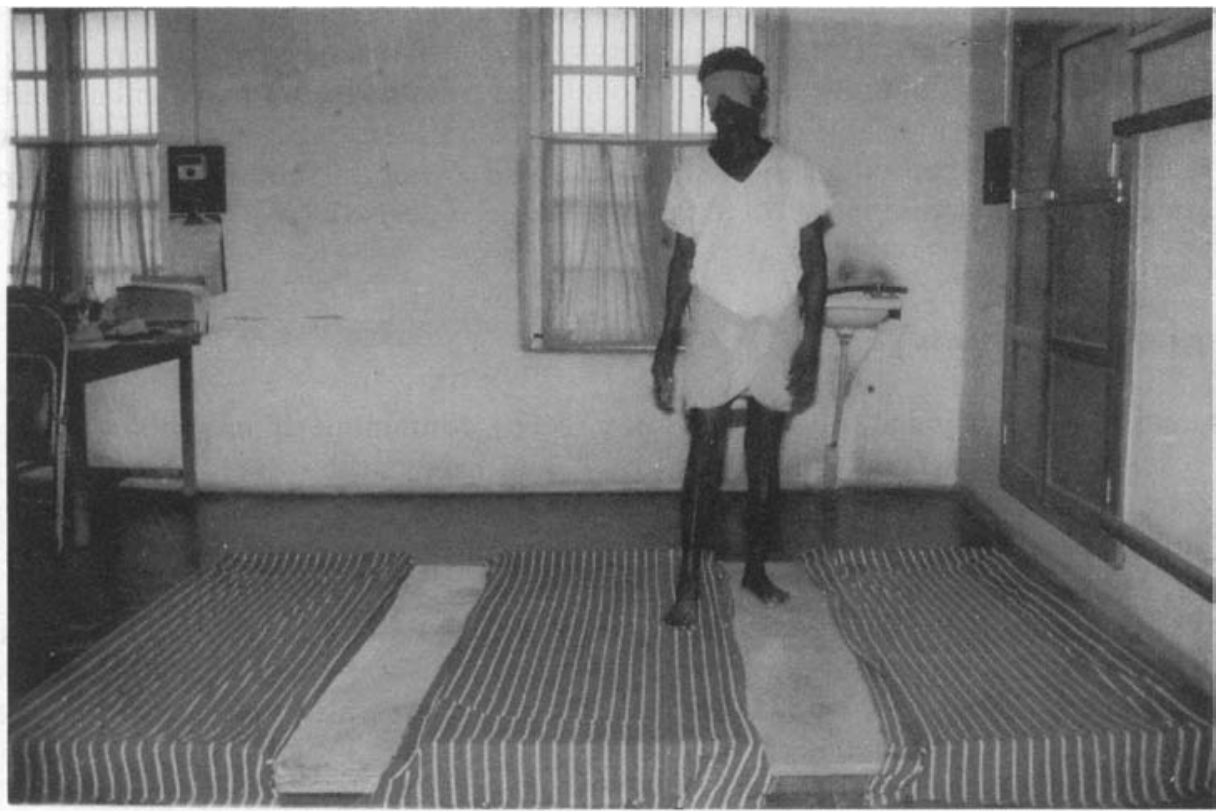

Figure 2. A blindfolded patient walks with 1 foot on a tray and the other on a platform trying to identify the material under foot. 
In addition to other sensory tests, this has been performed at our centre since April 1992 for leprosy patients with posterior tibial neuritis, symptoms of sensory and/or motor involvement of posterior tibial nerve and plantar ulcers. The treatment given to them varied between nonsteroidal anti-inflammatory drugs, corticosteroids, posterior tibial nerve decompression and nerve muscle graft. The test was repeated during followup of the 4 therapeutic regimens. The results reported here refer to the pre-operative findings for patients who underwent decompression or muscle graft operations. The category 'other' includes those treated with corticosteroids and nonsteroidal antiinflammatory drugs.

\section{Results}

Table 1. Texture test for foot

\begin{tabular}{|c|c|c|c|c|c|c|c|}
\hline & \multirow{3}{*}{$\begin{array}{l}\text { No. of } \\
\text { feet } \\
\text { tested }\end{array}$} & \multicolumn{6}{|c|}{ Findings } \\
\hline & & \multicolumn{3}{|c|}{ Positive } & \multicolumn{3}{|c|}{ Negative } \\
\hline & & Peb & $\mathrm{S}$ & Rub & Peb & $\mathrm{S}$ & Rub \\
\hline Controls & 40 & 40 & 40 & 40 & - & - & - \\
\hline Patients & & \multicolumn{6}{|c|}{ Preoperative and pretherapy findings } \\
\hline 1 Posterior tibial nerve muscle graft & 9 & 0 & 0 & 0 & 9 & 9 & 9 \\
\hline 2 Posterior tibial nerve decompression & 85 & 74 & 53 & 11 & 11 & 32 & 74 \\
\hline 3 Others & 29 & 26 & 18 & 2 & 3 & 11 & 27 \\
\hline
\end{tabular}

Peb, pebbles; S, sand; Rub, MCR.

\section{Discussion}

Sensory testing is a sensitive method in the follow-up of nerve involvement; as a prognostic test, it is also shown to be of use in early mild neuritis. ${ }^{3}$

Each sensory modality tested and recorded separately is an unreliable indicator of useful sensory function. Sensory discrimination and stereognostic sense are the true elements of useful sensory function. ${ }^{5}$

According to Moberg, most of the tests described were of academic nature and inadequate to determine whether the person could use their extremity with safety. ${ }^{1}$

Patients do not think in terms of sensory modalities. What is of immediate concern to them is whether or not the affected part has a protective sensation, ${ }^{6}$ because this is the major factor in ulcer formation. ${ }^{2}$

What is required is a simple test that can be conveniently and easily performed and a routine assessment for sensory function that is practicable, reproducible, clinically acceptable 5 and mimics normal conditions and sensory perception.

The test described in this paper involves texture discrimination and object identification. Texture discrimination is the ability to appreciate differences in the texture of the combined fabric and surfaces by the sensation aroused when the object and the skin are in contact with each other. 
The test objects we used are materials with which our patients are familiar. Being an agricultural area, most of our patients are bare-footed and walk on stones, mud, clay and sand.

This test differs from the conventional test in that the stimulus is not applied at any single point and is not aimed at testing a single sensory modality.

Another important difference is that the patients are asked to walk during the test. Movement is an essential component of discriminating textures and identifying objects.

\section{Conclusion}

This dynamic, inexpensive and functional test is considered as a significant and practical contribution to testing sensibility of the sole of the foot and is recommended as an additional method to evaluate the extent of the posterior tibial nerve involvement and the results of treatment.

As the threshold of the stimulus in this test is very high, it does not obviate the use of other methods with stimuli of lower threshold, particularly when seeking early signs of sensory impairment.

Being a test with high threshold stimulus, it is of definite use in selecting patients with no residual sensory (and motor) function for nerve muscle graft and for comparable controls for randomized study. In other patients who undergo nerve decompression and are given antireaction drugs to induce recovery of sensory function, this test is expected to be of use in prognostic evaluation and this aspect is under investigation.

\section{Acknowledgments}

The authors gratefully acknowledge the Superintendent and Administrator, Sacred Heart Leprosy Centre, for permitting them to use the material for this paper. They also thank Mr M. Jayaraman, Engineer, and Mr G. R. Paulraj, Occupational Therapy Department, who helped them in the construction of the trays and in the preparation of this manuscript.

\section{References}

1 Dellon AL. The sensational contributions of Erik Moberg. J Hand Surg (British) Volume, 190, 15B: 14-24.

2 Hammond CJ, Klenerman P. Protective sensation in the foot. Lepr Rev, 1988; 59: 347-54.

3 Naafs B, Dagne T. Sensory testing-a sensitive method in the follow-up of nerve involvement. Int J Lepr, 1977; 45: 364-8.

4 Pearson JMH. The evaluation of nerve damage in leprosy. Lepr Rev, 1982; 53: 119-30.

${ }^{5}$ Sir Sydney Sunderland. Nerve injuries and sensory function in nerve injuries and their repair. A critical appraisal. Churchill Livingstone, 1992; 305-31.

6 Von Prince K, Butler B. Measuring sensory function of the hand in peripheral nerve injuries. Am J Occ Therapy, 1967; 21: 385-95 